Isabelle Coelho da Silva, Josenildo Silva do Nascimento, Ana Carolina Costa Pereira

Estudando equação do $1^{o}$ grau por meio do uso de fontes históricas: o papiro de rhind

\title{
ESTUDANDO EQUAÇÃO DO 1 GRAU POR MEIO DO USO DE FONTES HISTÓRICAS: O PAPIRO DE RHIND
}

\author{
Isabelle Coelho da Silva \\ Universidade Estadual do Ceará \\ Josenildo Silva do Nascimento ${ }^{2}$ \\ Universidade Estadual do Ceará \\ Ana Carolina Costa Pereira ${ }^{3}$ \\ Universidade Estadual do Ceará
}

\section{Resumo}

Desde a criação dos Parâmetros Curriculares Nacionais na década de 90 do século passado, têm sido criadas várias discussões em relação à utilização das Tendências da Educação Matemática. Uma destas discussões é que muitos dos atuais professores da Educação Básica não estão preparados para fazer uso destas técnicas de aprendizagem. No entanto, este fato se mostra mais perceptível quando a tendência em questão é a História da Matemática. Então, com o intuito de providenciar uma maior instrução para a utilização deste recurso, propomos uma opção de aula sobre o conteúdo de Equações do $1^{\underline{o}}$ grau com base em uma abordagem histórica. Para isto, foi utilizado um documento egípcio antigo, conhecido como Papiro de Rhind, que é uma importante fonte de conhecimento matemático e que pode ser utilizado para ensinar diversos conteúdos. Através deste papiro foi introduzido o método da Falsa Posição, que está diretamente ligado aos primeiros indícios do uso do conceito de Equações do $1^{\mathrm{o}}$ grau. A partir da introdução do método, discutimos com os discentes a melhor maneira de se utilizar o método e se ele é um método válido para o aprendizado do conteúdo. Assim, foi visto que o método proporciona ao aluno uma forma diferente de resolver questões relacionadas às Equações do $1^{\circ} \underline{\text { grau}}$, dispondo de uma forma diferente daquela ensinada pelos professores na atualidade. Deste modo, percebemos que é possível inovar nas aulas tradicionais de matemática, dando ao aluno diversas opções para o desenvolvimento de seu aprendizado e propiciando um ambiente de discussão em que o conhecimento poderá ser construído com a participação de todos.

Palavras-chave: História da Matemática; Regra da Falsa Posição; Ensino de Matemática; Equação do Primeiro Grau; Tendências da Educação Matemática.

\section{Introdução}

A busca pelo modelo ideal de uma aula está sempre em foco. Contudo, o que é bom para determinado aluno, pode não ser bom para todos. Muitos professores ao planejar suas aulas têm disponível diversos recursos metodológicos que podem torná-las

\footnotetext{
1belle_da_silva@hotmail.com

2josenildo_silva23@hotmail.com

3 carolina.pereira@uece.br
}

Boletim Cearense de Educação e História da Matemática - ISSN: 2447-8504, Volume 02, Número 06, 37 - 48(2015) DOI: $10.30938 /$ bocehm.v2i6.16 
Isabelle Coelho da Silva, Josenildo Silva do Nascimento, Ana Carolina Costa Pereira

Estudando equação do $1^{\circ}$ grau por meio do uso de fontes históricas: o papiro de rhind

mais atrativas. Embora a aula expositiva seja a metodologia mais utilizada por esses professores, podem-se vincular alguns recursos diferenciados neste momento. Ela nunca pode ser o único recurso usado em classe e deve sempre fazer parte de uma sequência de atividades.

Desta maneira, o professor não apenas utilizará uma metodologia diferente, mas também tornará a aula mais agradável e acessível para todos os alunos. Então, torna-se necessário que o docente esteja em constante busca por métodos novos para ensinar a sua matéria. No caso da matemática, esta busca não é diferente e a pesquisa tem um papel fundamental para tornar a aula mais clara para os alunos. Bicudo (1993, p.22) fala que a pesquisa em Educação Matemática "permite que se compreenda a Matemática, o modo pelo qual ela é construída, os significados da Matemática no mundo atual”.

A partir da pesquisa em Educação Matemática têm-se desenvolvido o estudo de diversos recursos que intencionam um maior aprendizado na matéria. A História da Matemática é um desses recursos, ou seja, uma ferramenta que poderá ser utilizada em conjunto com a aula expositiva. Seu uso não está agregado a fornecer datas e fatos ocorridos no decorrer da história de certo conceito matemático, mas sim mostrar ao aluno como este originou-se, trabalhando com a matemática da época. Dessa forma, o aluno tem a escolha de optar pela matemática moderna apresentada pelo seu professor ou a origem do conceito estudado historicamente.

Nesse sentindo, a História da Matemática é um recurso muito importante para o Ensino de Matemática e sua inserção na sala de aula se mostra cada dia mais necessária. De acordo com Lutz (2006, p.2),

\begin{abstract}
os autores Miguel e Miorim (2005) não acreditam que exista "uma única História da Matemática da qual se possa fazer uso e abuso e que devesse ser recortada e inserida homeopaticamente no ensino. Eles entendem que histórias podem e devem constituir pontos de referência para a problematização pedagógica da cultura escolar e, mais particularmente, da cultura matemática e da educação matemática escolar, desde que sejam devidamente constituídas com fins explicitamente pedagógicos e organicamente articulados com as demais variáveis que intervêm no processo de ensino aprendizagem escolar da matemática”.
\end{abstract}

Entretanto, não há como dizer qual a melhor forma para utilizar a História da Matemática na educação, pois esta é uma técnica bastante abrangente, que permite seu uso correto de diversas formas, tentando abranger todos os alunos. Como foi mostrado anteriormente, há cinco formas de inserir a História da Matemática na sala de aula: o desenvolvimento de projetos inspirados pela história; o uso de aspectos culturais da Matemática numa perspectiva histórica; o tratamento detalhado de exemplos 
Isabelle Coelho da Silva, Josenildo Silva do Nascimento, Ana Carolina Costa Pereira

Estudando equação do $1^{o}$ grau por meio do uso de fontes históricas: o papiro de rhind

particulares; o aperfeiçoando o conhecimento matemático, por meio da História da Matemática; e o uso de fontes históricas.

Gomes e Rodrigues (2014, p.63) defendem o uso da História da Matemática quando falam que as referências históricas da Matemática visam "a busca da motivação do aluno, o qual, atualmente, sente muita necessidade de entender as aplicações e os motivos pelos quais surgiram certos conceitos e teorias trabalhadas na escola". Isto mostra que através da história pode-se responder às clássicas perguntas dos alunos: "por que eu tenho que estudar este conteúdo?" e "para que criaram este conteúdo?".

Neste sentido, os mesmo autores afirmam que

O trabalho com os conhecimentos históricos referentes à Matemática deve buscar dar ao educando uma visão mais crítica sobre os objetos de conhecimento, bem como fornecer informações culturais, sociológicas e antropológicas de grande valor formativo, ou seja, busca-se que a abordagem histórica da Matemática seja uma possibilidade de resgate da identidade cultural dos povos e das sociedades. (GOMES e RODRIGUES, 2014, p.58).

Dentro da área de História da Matemática, como citada anteriormente, existem cinco modos de inseri-la no ensino, dentre elas encontramos o uso de fontes históricas. Segundo Pereira e Pereira (2015, p. 68) "pesquisas na área da história com o uso de fontes, apontam que tal recurso é fundamental para o estudo de assuntos que buscam vestígios e testemunhos de um passado", porém, precisa-se ter "cuidado especial, pois a obra possui ideias entrelaçadas do autor, e mesmo examinando minuciosamente, algumas questões podem ficar sem respostas" (PEREIRA e PEREIRA, 2015, p. 70).

Para o ensino de matemática, a utilização de fontes históricas é indispensável, pois as sociedades antigas fizeram vários estudos e descobertas matemáticas, e, portanto há a necessidade da investigação de documentos que comprovem estes fatos e mostrem como e por que estes estudos foram feitos. Como exemplo de documento utilizado por pesquisadores no ensino de matemática, encontramos o Papiro de Moscou (figura 1), que é um papiro egípcio antigo com 25 problemas matemáticos envolvendo áreas, volume, medições, equações e outros conteúdos matemáticos, incluindo algumas questões incompreensíveis devido à degradação do documento.

Figura 1 - O Papiro de Moscou - Problema 14 em Hierático e Hieroglífico 
Isabelle Coelho da Silva, Josenildo Silva do Nascimento, Ana Carolina Costa Pereira

Estudando equação do lo grau por meio do uso de fontes históricas: o papiro de rhind

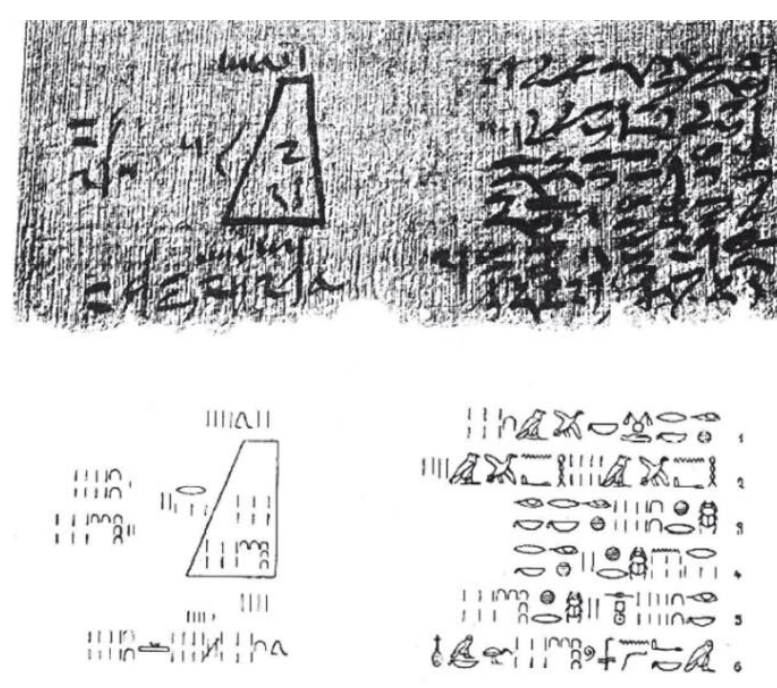

Fonte: Eves (2011, p. 86).

A fonte história pode ser um modo de estudar a matemática do passado, relacionando-a com o presente e adentrando na sala de aula como algo palpável e real para o aluno. Dentre os conteúdos que consideramos adequado para trabalhar com a História da Matemática, de modo a confrontar ideias e compará-la com a atualidade, está o estudo da equação do $1^{\circ}$ grau, ou mais especificamente, a equação linear. Esse conteúdo é iniciado no Ensino Fundamental, e importante para a fundamentação do curso de funções.

Assim sendo, nosso intuito é apresentar um modelo de aula utilizando a História da Matemática para estudar a equação do $1^{\underline{0}}$ grau, almejando proporcionar ao professor uma forma diferente de ensinar este conteúdo e tentar fazer uma aula mais acessível a todos os alunos. Nesse artigo, faremos uso da matemática egípcia, em particular, os problemas 23 a 27 contidos no Papiro de Rhind para relacionar o conteúdo pesquisado com a História e sua inserção no uso de fontes históricas no ensino.

\section{Uma proposta de aula}

O estudo da equação do $1^{\circ}$ grau é iniciado geralmente no $7^{\circ}$ ano do Ensino Fundamental em que, se formos analisar o livro didático encontrado no mercado brasileiro, este conteúdo é desenvolvido em aproximadamente dois capítulos. Nossa finalidade aqui é apresentar x aulas de 50min cada, de forma que o aluno possa ao final encontrar a solução da equação do $1^{\circ}$ grau. Ressaltamos ainda que o professor precisa estar preparado, dominar o conteúdo e a metodologia proposta, entretanto, caso isso não 
Isabelle Coelho da Silva, Josenildo Silva do Nascimento, Ana Carolina Costa Pereira

Estudando equação do $1^{o}$ grau por meio do uso de fontes históricas: o papiro de rhind

seja possível é orientado que ele não adentre a esse novo caminho. Para realização dessa atividade pode ser utilizada a sala de aula convencional com até 40 alunos. O trabalho em grupo será um forte recurso nesse modelo de aula.

Para iniciar a aula, o professor pode apresentar um panorama do desenvolvimento da Álgebra por meio da História, de forma bem simples mostrando seu surgimento em diferentes civilizações, tais como Egito, Grécia, Índia, entre outros. Em seguida pode-se propor um problema envolvendo o conteúdo que será estudado, questionando-os como seria possível resolver esse problema:

"Dois quintos do salário de Júlio são reservados para o aluguel e a metade é gasta com a alimentação, restando ainda $R \$ 45,00$ para gastos diversos. Qual é o salário de Júlio?"

Após essa discussão inicial, o professor pode questionar: Será que os povos antigos resolveriam este problema pelo mesmo método utilizado hoje?

Como os primeiros indícios do uso de equações aparecem no documento denominado Papiro de Rhind, apresentaremos uma técnica utilizada por eles para encontrar as soluções destes tipos de problemas, denominada Regra da Falsa Posição.

O papiro de Rhind ou Armes (figura 2) foi comprado por Henry Rhind em torno de 1680 em Luxor, uma cidade do sul do ${ }^{4}$ Egito. Ele Possui 84 problemas matemáticos envolvendo aritmética básica, frações, equações lineares e trigonometria básica. De acordo com o escriba Ahmesu, o conteúdo do papiro foi copiado por ele de outro documento, aproximadamente em 1650 a.C. a partir de escritos de 200 anos mais antigos. Segundo o estudo de Robins e Shute (1987), ele copiou o papiro no mês quatro da temporada de inundação do rio Nilo, no ano 33 do reinado de Auserre (Apophis). Ahmes também registra que ele está copiando um trabalho anterior, escrito no reinado de Ny-maat-re (Nymare), sexto rei da dinastia.

Figura 2 - "Tábua" inicial do Papiro de Rhind contendo o dobro das frações $\overline{3}, \overline{7}-(\overline{15})$.

\footnotetext{
${ }^{4}$ Alexander Henry Rhind foi advogado e antiquário escocês. Viajou, por razões de saúde, ao Egito em busca de um clima mais ameno, e lá começou a estudar objetos da Antiguidade. Comprou, por volta de 1850, em Luxor, no Egito, um papiro que continha textos matemáticos.
} 


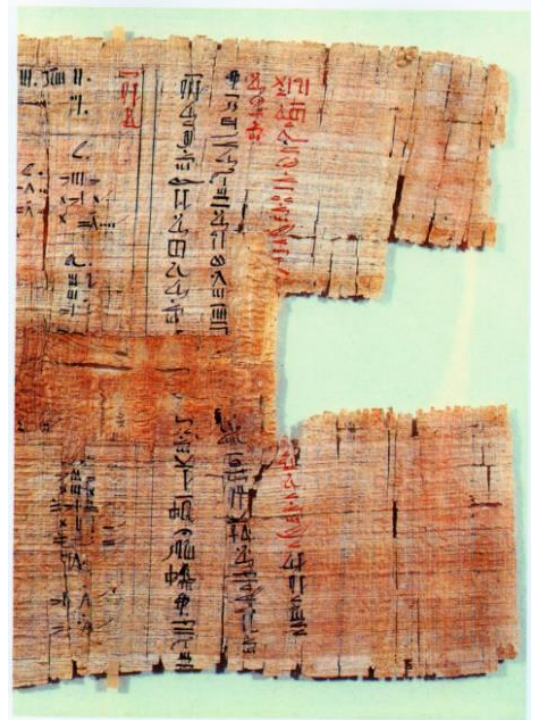

Fonte: Robins e Shute (1987, p. 65)

O papiro trata de diversos conteúdos matemáticos, gerando uma grande contribuição para a compreensão da matemática utilizada pela civilização egípcia desta época, colaborando para o desenvolvimento da História da Matemática e os estudos relacionados.

Alexander Rhind viajava por razões de saúde, ao Egito em busca de um clima mais ameno, e lá começou a estudar objetos da Antiguidade. Dentre esses objetos, ele adquiriu, em Luxor, dois documentos: o Papiro de Rhind e o rolo de couro comprado pelo museu britânico, em 1865, após sua morte. Este papiro está em exposição permanente atrás de um vidro na terceira sala egípcia no museu britânico.

Algumas das questões tratam de divisão de bens ou da safra que, se fossem resolvidas na atualidade, seria utilizado o conceito de equação do primeiro grau. Contudo, os egípcios não conheciam as técnicas que utilizamos nos dias atuais, como por exemplo, os números negativos e a linguagem matemática com os símbolos, portanto eles não poderiam resolver da forma que é ensinada na maioria das escolas hoje em dia. Através de pesquisas com base neste papiro, foi identificado que os egípcios utilizam um método que foi chamado de Regra da Falsa Posição.

A regra da falsa posição era utilizada pelos egípcios. Eles a utilizavam para designar valores desconhecidos, o cálculo aha (incógnita). Segundo (ZUIN, 2013, p. 5) "(...) utilizado nos papiros, se constitui em um método aritmético indireto para resolução de problemas com valores desconhecidos que recaem em uma equação do primeiro grau". 
Isabelle Coelho da Silva, Josenildo Silva do Nascimento, Ana Carolina Costa Pereira

Estudando equação do $1^{o}$ grau por meio do uso de fontes históricas: o papiro de rhind

De acordo com a publicação "Papiro de Rhind" no site do Instituto de Educação da Universidade de Lisboa, um exemplo que aparece no papiro é: "De uma quantidade de milho equivalente a vinte e uma medidas, um camponês deve dar ao Faraó uma parte igual à quinta parte da sua. Quanto lhe restará?", que pode ser utilizado na sala de aula para mostrar esta técnica.

Baseado em Sá (2008) o cálculo de aha ou regra da falsa posição tem origem indiana, provavelmente depois do século VII, porém existem registros mais antigos, em outras civilizações, como no Papiro Rhind. O mesmo autor define a regra do falso número como "um procedimento aritmético, envolvendo proporções, que parte de um número qualquer (nem tanto assim), denominado valor falso, para se obter o valor desejado no problema. (SÁ, 2008, p.42)"

Para solucionar o problema apresentado, começaremos adotando um valor falso para a incógnita. Para facilitar os cálculos, é importante que este valor seja um múltiplo dos denominadores das frações envolvidas. Adaptando o problema para a linguagem matemática, temos:

$$
\mathrm{a}+\frac{\mathrm{a}}{5}=21
$$

Adotaremos como falso o número 10, que é divisível por 5, e substituindo na equação temos:

$$
10+\frac{10}{5}=10+2=12 \text { (Valor falso) }
$$

Depois, com uma regra de três simples, podemos calcular o valor real de $\mathrm{x}$ do problema dado:

\begin{tabular}{l|c|c}
\hline & $\begin{array}{c}\text { Número } \\
\text { (quantidade) }\end{array}$ & Resultado \\
\hline Falso & 10 & 12 \\
\hline Verdadeiro & $\mathrm{a}$ & 21 \\
\hline \multicolumn{3}{c|}{$\frac{10}{\mathrm{a}}=\frac{12}{21}$} \\
$\mathrm{a}=\frac{10 \times 21}{12}=\frac{210}{12}=17,5$
\end{tabular}

Após introduzir essa nova forma de resolver equações lineares, o professor deve discutir com os alunos sobre os métodos que o aluno pode utilizar para resolver as equações, fazendo um confronto entre o antigo e o atual, de forma que os alunos possam mostrar as vantagens e desvantagens de cada método. Segue abaixo outros problemas 
Isabelle Coelho da Silva, Josenildo Silva do Nascimento, Ana Carolina Costa Pereira

Estudando equação do $1^{o}$ grau por meio do uso de fontes históricas: o papiro de rhind

encontrados no Papiro de Rhind e podem ser utilizados em sala de aula com os alunos (figura 3):

Problema 24: Uma quantidade e 1/7 da mesma dá um total de 19. (Qual é essa quantidade?)

Problema 25: Uma quantidade mais um meio dela dá 16. (Qual é essa quantidade?)

Problema 26: Uma quantidade adicionada ao seu 1/4 resulta 15. (Qual é essa quantidade?)

Problema 27: Uma quantidade e um quinto desta dá 21. (Qual é essa quantidade?)

Figura 3 - Problemas 24 - 30; final de 21 -23 (direito); final de 24 - 30 (esquerdo).

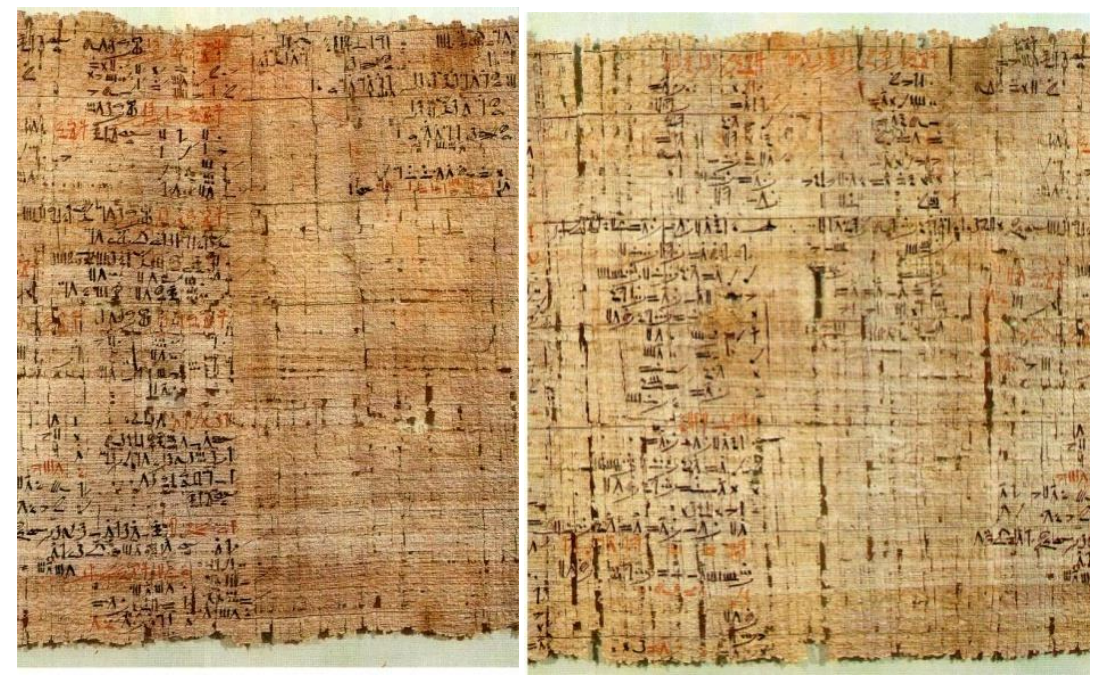

Fonte:Robins e Shute (1987)

Como notamos, a Regra da Falsa Posição é aplicável para expressões da forma $\mathrm{ax}=\mathrm{b}$, porém, para expressões do tipo $\mathrm{ax}+\mathrm{b}=\mathrm{c}$ este método é ineficiente.

De acordo com Guelli (1989, p. 21) "supostamente, já antes de Cristo, os babilônios e os chineses usavam, para este caso, a regra da "dupla falsa posição"', que funciona assim:

Para encontrarmos $\mathrm{x}$, tal que $\mathrm{ax}+\mathrm{b}=\mathrm{c}$, devemos, primeiramente, considerar $\mathrm{a}$ função $\mathrm{f}(\mathrm{x})=\mathrm{ax}+\mathrm{b}, \operatorname{logo}$ após atribuiremos a $\mathrm{x}$ dois valores "falsos" $\mathrm{x}_{1}$ e $\mathrm{x}_{2}$, e calcularemos $\mathrm{f}\left(\mathrm{x}_{1}\right)$ e $\mathrm{f}\left(\mathrm{x}_{2}\right)$, daí expressaremos a seguinte proporção:

$$
\frac{f\left(x_{1}\right)-c}{x_{1}-x}=\frac{f\left(x_{2}\right)-c}{x_{2}-x}
$$

Tomemos de exemplo o mesmo visto anteriormente, porém, adaptaremos o problema ao caso da Regra da Dupla Falsa Posição, logo o problema ficará assim: “De 
Isabelle Coelho da Silva, Josenildo Silva do Nascimento, Ana Carolina Costa Pereira

Estudando equação do $1^{\circ}$ grau por meio do uso de fontes históricas: o papiro de rhind

uma quantidade de milho equivalente a vinte e quatro medidas, um camponês deve dar ao Faraó uma parte igual à quinta parte somado com três medidas da sua. Quanto lhe restará?".

Em linguagem de hoje o exemplo seria expresso da forma que se segue:

$$
\frac{6}{5} x+3=24
$$

Como explicamos anteriormente, vamos considerar primeiro, a função dada por $f(x)=a x+b$. Portanto nossa função é $f(x)=\frac{6}{5} x+3$.Adotaremos $x_{1}=5$ e $x_{2}=10$, substituindo na equação temos:

$$
\begin{aligned}
& f\left(x_{1}\right)=\frac{6}{5} \times 5+3=6+3=9 \text { (Valor Falso) } \\
& f\left(x_{2}\right)=\frac{6}{5} \times 10+3=12+3=15 \text { (Valor Falso) }
\end{aligned}
$$

Agora, montemos e calculemos a proporção:

$$
\begin{gathered}
\frac{f\left(x_{1}\right)-c}{x_{1}-x}=\frac{f\left(x_{2}\right)-c}{x_{2}-x} \\
\frac{9-24}{5-x}=\frac{15-24}{10-x} \\
\frac{-15}{5-x}=\frac{-9}{10-x} \\
x=\frac{-9 * 5-(-15) * 10}{15-9} \\
x=\frac{105}{6} \\
x=17,5
\end{gathered}
$$

Notamos que os dois métodos chegam aos valores exatos de $x$, claro que sempre se tratando de equação de $1^{\circ}$ grau.

Caso formos aprofundar mais esta regra, iremos notar que ela foi bastante utilizada ao longo do tempo e das civilizações, já atualmente "reconhecemos a regra da dupla falsa posição como um processo de aproximação [...] é o que chamamos de processo da interpolação" (GUELLI, 1989, p. 22). Sendo assim, será que nos dias de hoje, com toda a preocupação da otimização dos processos operatórios, as regras de falsa posição e dupla falsa posição poderia ser uma boa alternativa para ser exposto em nossas salas de aula?

\section{Considerações Finais}


Isabelle Coelho da Silva, Josenildo Silva do Nascimento, Ana Carolina Costa Pereira

Estudando equação do $1^{o}$ grau por meio do uso de fontes históricas: o papiro de rhind

Não é fácil para o professor, com a vida atribulada e com várias aulas semanais para ministrar, preparar aulas envolvendo várias metodologias: Jogos, Material Manipulativo, Informática Educativa, Resolução de Problemas, História da Matemática, entre outras. Embora, muitos autores disponibilizem publicações para facilitar esse planejamento, em muitas dessas tendências ainda são insuficientes os materiais escritos na área.

A História da Matemática é um dos caminhos de fazer Matemática em sala de aula proposto pelos Parâmetros Curriculares Nacionais - PCN (1998) que está crescendo no Brasil, principalmente, devido a eventos e publicações específicas da área, chegando até mesmo às escolas da Educação Básica. Embora esse crescimento já seja visível, ainda encontramos poucos materiais destinados a seu uso e indicações de propostas de aulas planejáveis que chega à sala de aula.

Assim, uma proposta do ensino de equação do primeiro grau com o Papiro de Rhind remete ao uso da História da Matemática através das fontes históricas. Como uma das funções da fonte histórica é demonstrar como era utilizada a matemática no momento daquele documento, a regra da falsa posição será o meio que os egípcios desenvolveram para resolver problemas deste conteúdo, e o Papiro de Rhind será a fonte que mostrará como era feita a regra da falsa posição naquela época.

Nossa proposta é iniciar uma série artigos mostrando o uso da História da Matemática para o professor aplicar na sala de aula. Um passo a passo de cada etapa que ele deverá seguir e indicação de bibliografia especifica para cada assunto proposto. Nesse sentido, iniciamos o conteúdo do $7^{0}$ no do Ensino Fundamental, resolução da equação do $1^{\mathrm{o}}$ grau para que o professor possa sair do tradicionalismo das aulas expositivas e adentrar nos caminhos que a História da Matemática nos leva.

Deste modo, é necessário refletirmos sobre a importância e o direcionamento que se tem dado ao foco dessas publicações, se está mais voltado para o científico ou para a sala de aula. Assim, será possível tratar do uso da História da Matemática no ensino de forma mais efetiva, focando na preparação do professor e futuro professor para utilizar este recurso em prol do aprendizado dos alunos.

\section{Referências}


Isabelle Coelho da Silva, Josenildo Silva do Nascimento, Ana Carolina Costa Pereira Estudando equação do $1^{o}$ grau por meio do uso de fontes históricas: o papiro de rhind

BICUDO, Maria Aparecida Viggiani (1993). Pesquisa em Educação Matemática. Pró-Posições. v. 4, n 1, p. 18- 23. Disponível em:

http://www.proposicoes.fe.unicamp.br/proposicoes/textos/10-artigosbicudomav.pdf

BRASIL. Ministério da Educação e Cultura. EC. Secretaria de Educação Fundamental. Parâmetros Curriculares Nacionais - Matemática (5ª a 8ª série). Brasília, 1998.

D'AMBROSIO, Beatriz Silva. Como ensinar matemática hoje? Temas e Debates. SBEM. Ano II, nº 2. Brasília. 1989. P. 15-19.

EVES, Howard. Introdução à História da Matemática. Tradução Hygino H. Domingues. 5a ed. - Campinas, SP: Editora da Unicamp, 2011.

FIORENTINI, Dario; MIORIM, Maria Ângela; MIGUEL, Antônio. Contribuição para um Repensar... a Educação Algébrica Elementar. Pro-posições, Campinas, v. 4, n. 1, p.78-91, mar. 1993.

GOMES, Thiago de Azevedo, RODRIGUES, Chang Kuo (2014). A evolução das tendências da educação matemática e o enfoque da história da matemática no ensino. Disponível em

http://publicacoes.unigranrio.edu.br/index.php/recm/article/viewFile/2687/1264

GUELLI, Oscar. A regra da falsa posição. Revista do Professor de Matemática, São Paulo, v. 15, n. 1, p. 18-22, 1989.

LUTZ, Michele Mello. A História da Matemática no Contexto do Livro Didático. 2006. 8 f. Monografia (Graduação) - Universidade Católica de Brasília, Brasília, 2006. Disponível em http://repositorio.ucb.br/jspui/bitstream/10869/1638/1/Michele\%20Mello\%20Lutz.pdf Acesso em 02.01.16

PATERLINI, Roberto Ribeiro. O que é o método genético para o ensino da matemática. Disponível em:

<http://www.dm.ufscar.br/hp/hp591/hp591002/hp5910022/hp5910022.html>. Acesso em: 23 ago. 2013.

PEREIRA, Ana Carolina Costa; PEREIRA, Daniele Esteves. Ensaio sobre o uso de fontes históricas no ensino de matemática. Rematec: Revista de Matemática, Ensino e Cultura, Natal, v. 10, n. 18, p.65-78, jan.- Abr. de 2015.

ROBINS, Gay; SHUTE, Charles. The Rhind Mathematical Papyrus: an ancient Egyptian text. London: British Museum Publications, 1987.

SÁ, Ilydio Pereira de. A Regra da Falsa Posição. Pesquisas e Práticas em Educação Matemática, Vassouras, v. 2, n. 1, p.41-50, jan./jun., 2008.

ZUIN, Elenice de Souza Lodron. Os papiros egípcios como fontes para um trabalho com a história da matemática em sala de aula. In: Encontro Nacional de Educação Matemática, 11, 2013, Curitiba. Anais... (CD-ROM) Curitiba: PUC-PR, 2013. 
Isabelle Coelho da Silva, Josenildo Silva do Nascimento, Ana Carolina Costa Pereira

Estudando equação do $1^{o}$ grau por meio do uso de fontes históricas: o papiro de rhind 